\title{
Lycopene from two food sources does not affect antioxidant or cholesterol status of middle-aged adults
} \author{
JK Collins*1, BH Arjmandi², PL Claypool ${ }^{3}$, P Perkins-Veazie' ${ }^{1}$, RA Baker ${ }^{4}$ and \\ BA Clevidence ${ }^{5}$
}

Address: ${ }^{1}$ USDA, ARS, South Central Agricultural Research Laboratory, Lane, OK, USA, ${ }^{2}$ Dept. Nutritional Sciences, Oklahoma State University, Stillwater, OK, USA, ${ }^{3}$ Dept. Statistics, Oklahoma State University, Stillwater, OK, USA, ${ }^{4}$ Retired, USDA, ARS, Citrus and Subtropical Products Laboratory, Winter Haven, FL, USA and ${ }^{5}$ USDA, ARS, Diet and Human Performance Laboratory, Beltsville, MD, USA

Email: JK Collins* - jcollins-usda@lane-ag.org; BH Arjmandi - arjmand@okstate.edu; PL Claypool - plcstat@okstate.edu; P PerkinsVeazie - pperkins-usda@lane-ag.org; RA Baker - rbaker11@tampabay.rr.com; BA Clevidence - Clevideb@ba.ars.usda.gov

* Corresponding author

Published: 15 September 2004

Nutrition Journal 2004, 3:15 doi:10.1/86/1475-289|-3-15

This article is available from: http://www.nutritionj.com/content/3/I/l5

(c) 2004 Collins et al; licensee BioMed Central Ltd.

This is an open-access article distributed under the terms of the Creative Commons Attribution License (http://creativecommons.org/licenses/by/2.0), which permits unrestricted use, distribution, and reproduction in any medium, provided the original work is properly cited.
Received: 13 August 2004

Accepted: I5 September 2004

\begin{abstract}
Background: Epidemiological studies have reported associations between reduced cardiovascular disease and diets rich in tomato and/or lycopene. Intervention studies have shown that lycopenecontaining foods may reduce cholesterol levels and lipid peroxidation, factors implicated in the initiation of cardiovascular disease. The objective of this study was to determine whether consumption of lycopene rich foods conferred cardiovascular protection to middle-aged adults as indicated by plasma lipid concentrations and measures of ex vivo antioxidants.
\end{abstract}

Methods: Ten healthy men and women consumed a low lycopene diet with no added lycopene (control treatment) or supplemented with watermelon or tomato juice each containing $20 \mathrm{mg}$ lycopene. Subjects consumed each treatment for three weeks in a crossover design. Plasma, collected weekly was analyzed for total cholesterol, high density lipoprotein cholesterol (HDL-C) and triglyceride concentrations and for the antioxidant biomarkers of malondialdehyde formation products (MDA), plasma glutathione peroxidase (GPX) and ferric reducing ability of plasma (FRAP). Data were analyzed using Proc Mixed Procedure and associations between antioxidant and lipid measures were identified by Pearson's product moment correlation analysis.

Results: Compared to the control diet, the lycopene-containing foods did not affect plasma lipid concentrations or antioxidant biomarkers. Women had higher total cholesterol, HDL-C and triglyceride concentrations than did the men. Total cholesterol was positively correlated to MDA and FRAP while HDL-C was positively correlated to MDA and GPX. GPX was negatively correlated to triglyceride concentration.

Conclusions: The inclusion of watermelon or tomato juice containing $20 \mathrm{mg}$ lycopene did not affect plasma lipid concentrations or antioxidant status of healthy subjects. However, plasma cholesterol levels impacted the results of MDA and FRAP antioxidant tests. 


\section{Background}

Watermelons and tomatoes are good sources of the carotenoid lycopene $[1,2]$. However, bioavailability of lycopene is not directly related to plant content, and depends in a large part upon plant matrix effects. In tomatoes, heat processing and homogenization breaks protein-carotenoid complexes, releases lycopene from cell wall linkages and improves human uptake of this compound [3-6], while heat processing is not necessary for adequate uptake of lycopene from watermelon juice [7]. Extracts of both foods exhibit antioxidant activity in vitro and function is attributed to lycopene since isolated lycopene demonstrates strong oxygen and peroxy radical scavenging properties [8-10].

Recent epidemiological studies have linked reductions in risks of cardiovascular disease with diets rich in lycopene containing foods. These reductions in risk have been primarily attributed to the antioxidant properties of lycopene $[11,12]$. Improved antioxidant parameters of lymphocytes have been reported in clinical trials that supplemented diets with $16.5 \mathrm{mg}$ and $40 \mathrm{mg}$ /day of lycopene from tomato puree and tomato juice, respectively $[13,14]$. Other clinical trials have shown reductions in low-density lipoprotein (LDL) oxidation resulting from lycopene supplementation [15-17]. LDL contains unsaturated fatty acids and can be oxidized by free radicals and peroxidizing agents. Since lycopene is primarily attached to LDL in plasma, it may protect against atherosclerosis through inhibition of lipid peroxidation and foam cell production $[12,18]$.

Other studies have assessed response of plasma lipids to lycopene-rich diets. In one study, six healthy men were supplemented with $60 \mathrm{mg} /$ day for three months with tomato lycopene (LycoRed) with a $14 \%$ reduction in LDL$\mathrm{C}$ and no change in HDL-C [19]. Researchers concluded that lycopene was involved in controlling cholesterol synthesis and found the same results in a macrophage cell study [19]. It is not known if other lycopene containing foods can act ex vivo as antioxidants or alter cholesterol levels.

The objectives of this study were to compare the ability of two lycopene containing foods, tomato and watermelon to provide cardiovascular protection to middle-aged adults by measuring changes in cholesterol levels and antioxidant ex vivo biomarkers.

\section{Methods}

\section{Experimental Design}

Samples for this study came from a larger study, which has been reported in detail [7]. This study was a diet-controlled, repeated measures crossover design with ten healthy non-smoking subjects, five men (average age 49 years) and five women (average age 51 years) recruited from the Beltsville, MD area (Table 1). In addition to a base diet, which provided $34 \%$ of energy from fat and minimal amounts of lycopene, subjects were randomly assigned to receive three dietary treatments for 3 weeks each: 1) control (no added lycopene); 2) $20.1 \mathrm{mg}$ lycopene per day from watermelon juice; and 3) $18.4 \mathrm{mg}$ lycopene per day from tomato juice. All subjects followed a low-lycopene diet for two weeks before the first treatment and during the four-week washout periods between treatments. Total study duration was 19 weeks. During treatment periods, all meals were prepared and consumed Monday through Friday at the Beltsville Human Nutrition Research Center's Human Studies Facility, and weekend meals were packed for off-site consumption. Blood was drawn from fasted subjects before treatment (the day before the start of study and on the first day of the study), prior to treatment and weekly during treatment. Plasma was separated from whole blood by centrifugation and stored at $-80^{\circ} \mathrm{C}$ until analyzed for cholesterol and antioxidant activity.

\section{Juice Treatments}

Watermelon juice for the study was prepared at a pilot plant at the USDA Citrus and Subtropical Products Laboratory, Winter Haven, FL without heat treatment as previously described [7]. Canned commercial tomato juice (Campbell's, Camden, NJ) was used for the tomato intervention. Juices were analyzed for carotenoid content using established extraction procedures with reversed phase HPLC with photo diode array detector (Waters Corp, Franklin, MA) [7]. For watermelon treatment, subjects were given one bottle of juice (260 g each) at breakfast, lunch and dinner, which provided daily totals of $20.1 \mathrm{mg}$ lycopene, $0.90 \mathrm{mg}$ phytoene, $0.45 \mathrm{mg}$ phytofluene and $2.5 \mathrm{mg}$ beta carotene. The juice contained 94\% trans lycopene and 6\% cis isomers, primarily 5-cis and 13-cis with minimal amounts of other cis isomers [7]. For tomato juice treatment, subjects were given one serving (122 g each) at breakfast and dinner, which provided daily totals of $18.4 \mathrm{mg}$ lycopene, $2.1 \mathrm{mg}$ phytoene, $1.1 \mathrm{mg}$ phytofluene and $0.6 \mathrm{mg}$ beta carotene with $89 \%$ of the lycopene as trans lycopene and $10.8 \%$ cis isomers, primarily identified as 5-cis, 9-cis, 13-cis, and 15-cis, and minimal amounts of other cis isomers [7].

Table I: Description of human clinical study participants.

\begin{tabular}{lccc}
\hline Gender & N & Age (Range) yr & BMI (Range) Kg/m² \\
\hline Men & 5 & $49(43-68)$ & $26.3(23.0-29.5)$ \\
Women & 5 & $51(35-63)$ & $29.1(23.5-34.5)$
\end{tabular}




\section{Cholesterol Analysis}

Plasma samples were thawed on ice for four hours then mixed by vortexing, prior to preparing for assays. Serum total cholesterol and triglyceride concentrations were determined enzymatically using kits from Roche Diagnostics (Sommerville, NJ). Serum HDL-cholesterol was determined by a direct method (Unimate HDL Direct ; Roche Diagnostics, Indianapolis, IN) that utilizes the combined action of polymers, polyanions, and detergent to solubilize cholesterol from HDL but not from VLDL, LDL, and chylomicrons as previously described [20]. Analysis was performed on a Cobas-Fara II Clinical Analyzer (Montclair, NJ) using commercially available calibrators and quality control standards (Roche Diagnostics, Indianapolis, IN).

\section{Plasma Glutathione Peroxidase Assay}

Plasma from subjects was analyzed for plasma glutathione peroxidase using an ELISA kit (OXIS Internatl., Portland, OR). Two replicates per sample of $20 \mu \mathrm{l}$ of plasma were diluted 1:25 with TRIS-HCl buffer then pippetted into pre-coated polyclonal antibodies microplate wells specific for human plasma glutathione peroxidase (GPX). The amount of enzyme present was determined by reaction with para-nitrophenyl-phosphate and was read using a microplate reader at $405 \mathrm{~nm}$ (Elx 808 Ultra Microplate Reader, Bio-Tek Instruments Inc., Winooski, VT). The concentration of plasma GPX was determined from a standard curve for each plate using five dilutions of GPX standard.

\section{Plasma lipid peroxidation}

Malondialdehyde compounds were determined colorimetrically using a commercial kit specific for measuring free and total malondialdehyde compounds (OXIS Internatl., Portland, OR). Two replicates per sample of $210 \mu \mathrm{l}$ of plasma were added to each test tube with $11 \mu \mathrm{l}$ of 500 $\mathrm{mM}$ butylated hydroxytoluene and $5.3 \mu \mathrm{l}$ of concentrated hydrochloric acid. Tubes were capped, mixed then incubated at $60^{\circ} \mathrm{C}$ for 80 minutes, cooled to room temperature and $680 \mu \mathrm{l}$ of $\mathrm{N}$-methyl-2-phenylindole in acetonitrile was added. Then tubes were mixed, and centrifuged at $13,000 \mathrm{~g}$ for 5 minutes. New tubes were prepared and $660 \mu \mathrm{l}$ of clear supernatant was added with 115 $\mu \mathrm{l}$ of concentrated $\mathrm{HCl}$. Tubes were capped, mixed and incubated at $45^{\circ} \mathrm{C}$ for 60 minutes. Samples were centrifuged at 13,000 $\mathrm{g}$ for $5 \mathrm{~min}$ and the supernatant was read on a spectrophometer at $575 \mathrm{~nm}$. Concentration of samples was determined using a five point standard curve.

\section{Ferric reducing ability of plasma assay}

This assay was conducted according to previously published methods [1]. In brief, three reagents were used: 1) sodium acetate, acetic acid buffer ( $\mathrm{pH} \mathrm{3.6);2)10} \mathrm{mmol/L}$ solution of 2, 4,6-tripyridyl-s-triazine in a $40 \mathrm{mmol} / \mathrm{L}$ solution of hydrochloric acid (Sigma, St. Louis, MO); and 3) $20 \mathrm{mmol} / \mathrm{L}$ solution of ferric chloride hexahydrate prepared in double deionized water. The FRAP reagent was prepared daily with $25 \mathrm{ml}$ of reagent one, $2.5 \mathrm{ml}$ reagent two and three that were heated to $37^{\circ} \mathrm{C}$ before using [21]. The assay was conducted with $10 \mathrm{uL}$ of plasma that was diluted with $30 \mu \mathrm{l}$ of ddi water. Sample was added to reagent in cuvettes with an autosampler and then read on a COBAS FARA II spectrofluorometric centrifugal analyzer (Roche, Montclair, NJ) at $593 \mathrm{~nm}$ at four minutes. FRAP values were determined from a five point curve using a trolox (vitamin E analog) standard. Standard curves were run after every 90 samples.

Experimental procedures for the clinical trial were approved by the Institutional Review Board at the Johns Hopkins University Bloomberg School of Hygiene and Public Health; subjects gave their written informed consent to participate. The plasma cholesterol and antioxidant studies were approved by the Institutional Review Board at Oklahoma State University, Stillwater, OK. Data were analyzed using Proc Mixed Procedure and mean separation was performed using LSMEANS, correlation analysis was performed using Spearman's Correlation Coefficient Analysis (SAS Statistical Analysis Software, version 8.2, SAS Institute, Cary, NC).

\section{Results}

Because there were significant four way interactions with gender $\times$ intervention period $\times$ treatment $\times$ weeks with MDA, FRAP, GPX and cholesterol analysis, trends by treatment, intervention period or week of treatment were not seen. Supplementing the diet with $20 \mathrm{mg} /$ day of lycopene of either food did not change the plasma antioxidant status of the subjects and values ranged from 0.66-2.20, 540-1094, and 1296-2596:mol/L for MDA, FRAP and GPX respectively. These levels are similar to levels reported for healthy subjects in other studie [22,23].

Intervention with $20 \mathrm{mg}$ of lycopene to the diet of subjects did not alter their total cholesterol, HDL-C or triglyceride status. However, there were gender differences and the women had higher average levels of plasma triglycerides, total cholesterol and HDL-C than men (Figure 1). The higher cholesterol levels for women compared to men in this study were not unusual since women in this age range often have higher cholesterol levels than men, a phenomenon related to decreased estrogen production [24,25]. In this study, menopausal information was not recorded.

There was a significant positive correlation between each pair of total cholesterol and MDA and MDA and FRAP and between HDL-C and MDA and HDL-C and GPX. A significant negative correlation was found between triglycerides and GPX (Table 2). 


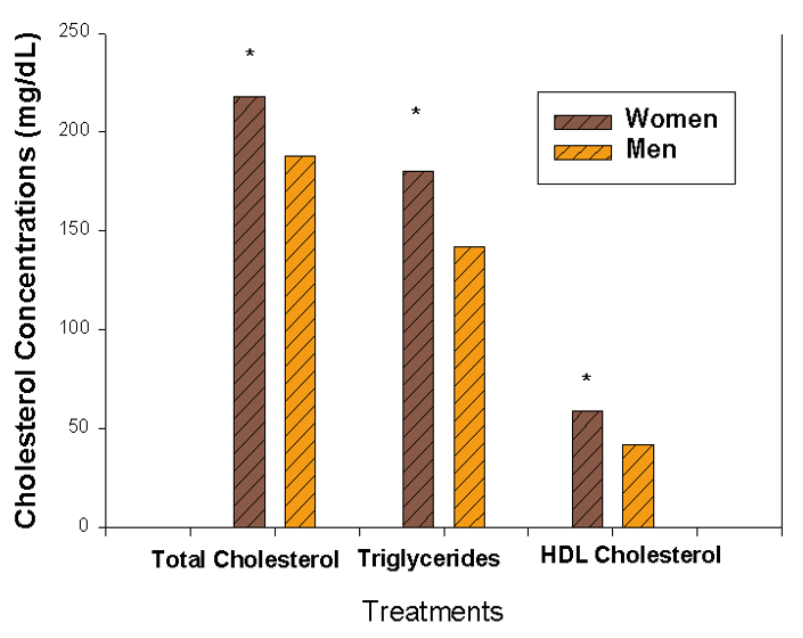

Figure I

Mean plasma total cholesterol, triglycerides, and high density lipoprotein $(\mathrm{HDL})$ cholesterol $(\mathrm{mg} / \mathrm{dl})$ of 5 men and 5 women supplemented for 3 week with no lycopene (control), $20 \mathrm{mg}$ lycopene from watermelon juice and $20 \mathrm{mg}$ lycopene from tomato juice. *Represents significance $p<0.05$.

Table 2: Spearman's Correlation Coefficients between antioxidant tests of malondialdehyde (MDA) ferric reducing ability of plasma (FRAP), and plasma glutathione peroxidase (GPX) and cholesterol measurements.

\begin{tabular}{llll}
\hline Variable & MDA & FRAP & GPX \\
\hline Total cholesterol & $0.547^{* *}$ & $0.325^{* *}$ & 0.003 \\
HDL-C & $0.563^{* *}$ & 0.059 & $0.294^{* *}$ \\
Triglycerides & 0.219 & 0.037 & $-0.229^{*}$ \\
MDA &. & $0.474^{* *}$ & 0.180 \\
FRAP & $0.474^{* *}$ &. & 0.077
\end{tabular}

Correlations significant at the $0.05^{*}$ and $0.0 I^{* *}$ level.

Because of the correlation between cholesterol concentrations and antioxidant analysis, a preliminary analysis of data was conducted to determine if cholesterol levels impacted antioxidant results. Subjects were separated into two groups based upon baseline concentrations of plasma triglycerides, total cholesterol and LDL-C above or below 200, 180 and 160, respectively. Five subjects, two men and three women, fit the criteria of moderately hypercholesterolemic (Table 3).

Analyses showed an interaction of cholesterol level $x$ treatment period $\times$ treatment factor for MDA and FRAP analysis. Higher MDA and FRAP levels were found in the group having higher cholesterol levels compared to the other group (Table 4). No trend with cholesterol level and glutathione peroxidase was found.

\section{Discussion}

We found no improvement in the antioxidant status of healthy middle-aged adults supplemented with two lycopene-containing foods. In previous antioxidant studies, reduced lipid peroxidation was reported in subjects supplemented from one to four weeks with 5 to $45 \mathrm{mg}$ lycopene containing tomato products $[15,16,23,26]$. However, in each of these studies, the diet was not controlled. When healthy elderly subjects in a diet controlled study were supplemented with $13.3 \mathrm{mg}$ of tomato lycopene (LycoRed) for 12 weeks, lycopene intervention did not significantly change LDL oxidation, as measured by the rate of conjugated diene production [27].

The reports from lycopene intervention studies that measured FRAP activity are not in agreement. One study reported improvement in FRAP levels of plasma in subjects supplemented with tomato juice and olive oil [28], while two other tomato juice intervention studies reported no improvement in plasma antioxidant levels after lycopene supplementation as measured by Trolox equivalent antioxidant capacity (TEAC), radical trapping antioxidant parameter assay (TRAP), and FRAP $[3,23]$. Researchers in one study found that the FRAP assay was more accurate when measuring the antioxidant activity of water-soluble antioxidants [23]. They thought full expression of the antioxidant activity was not identified from lycopene in this assay since it is a lipophyllic compound. Curiously, both watermelon and tomato contain other water-soluble compounds that are reported to have antioxidant activity that reacts in vitro in the FRAP assay $[9,29]$. In this study, contribution of these water-soluble compounds in changes in plasma FRAP activity with either food intervention compared to the control was not found.

Unlike a previous report by Fuhrman et al., neither lycopene intervention with watermelon nor tomato affected cholesterol levels [19]. Differences in results may have been due to lycopene dosage level. In that study [19] the subjects were supplemented with $60 \mathrm{mg} /$ day for three months, however diet was not controlled.

Fruits and vegetables are excellent sources of antioxidant compounds and the average American consumes only 1.5 and 3.1 servings per day [45]. In many of the studies where antioxidant protection with lycopene containing foods was reported, subjects consumed their normal diet that may or may not have met the recommended servings of fruits and vegetables $[13,23,26,31,32]$. Increasing fruit and vegetable consumption to 12 servings per day compared to 5.8 servings, without the addition of other diet 
Table 3: Separation of subjects by baseline cholesterol levels from a watermelon and tomato juice lycopene intervention study, $\mathbf{n}=\mathbf{5}$ for each group.

\begin{tabular}{cccc}
\hline Cholesterol Group & Total Cholesterol mg/dl & Triglycerides mg/dl & HDL-Cmg/dl \\
\hline 1 & $229.3 \pm 4.9$ & $190.9 \pm 12.8$ & $59.1 \pm 2.9$ \\
2 & $176.6 \pm 2.5$ & $129.7 \pm 5.2$ & $46.9 \pm 2.1$ \\
\hline
\end{tabular}

Data represents mean \pm SE

Table 4: Total, triglyceride, high density lipoprotein (HDL-C cholesterol and antioxidant analysis of malondialdehyde (MDA), glutathione peroxidase (GPX) and ferric reducing ability of of plasma (FRAP) after 4 week lycopene depletion and three weeks of intervention with watermelon and tomato juice $(20 \mathrm{mg}$ lycopene/day). Subjects were separated into 2 groups based upon cholesterol levels (see Table 3).

\begin{tabular}{|c|c|c|c|c|c|c|c|c|c|c|c|c|c|}
\hline $\begin{array}{c}\text { Cholesterol } \\
\text { Group }\end{array}$ & Analysis & Depletion & & SE & Control & & SE & Watermelon & & SE & Tomato & & SE \\
\hline & Total Cholesterol (mg/dl) & 220.9 & \pm & 9.5 & 223.4 & \pm & 7.9 & 224.6 & \pm & 8.2 & 233.6 & \pm & 6.2 \\
\hline & Triglycerides $(\mathrm{mg} / \mathrm{dl})$ & 185.9 & \pm & 16.9 & 181.7 & \pm & 16.9 & 198.9 & \pm & 18.3 & 174.7 & \pm & 15.6 \\
\hline \multirow[t]{6}{*}{1} & HDL-C (mg/dl) & 56.9 & \pm & 5.15 & 58.65 & \pm & 4.31 & 58.00 & \pm & 5.96 & 59.38 & \pm & 4.55 \\
\hline & MDA (umol/L) & 1.21 & \pm & 0.11 & 1.12 & \pm & 0.11 & 1.15 & \pm & 0.12 & 1.37 & \pm & 0.11 \\
\hline & GPX (umol/L) & 2728 & \pm & 219 & 2728 & \pm & 222 & 2263 & \pm & 169 & 2574 & \pm & 187 \\
\hline & FRAP (umol/L) & 831.6 & \pm & 24.9 & 871.7 & \pm & 26.7 & 900.9 & \pm & 25.2 & 861.6 & \pm & 23.4 \\
\hline & Total Cholesterol (mg/dl) & 182.6 & \pm & 4.2 & 173.3 & \pm & 3.3 & 186.1 & \pm & 6.4 & 173.1 & \pm & 2.8 \\
\hline & Triglycerides $(\mathrm{mg} / \mathrm{dl})$ & 129.4 & \pm & 8.3 & 128.7 & \pm & 7.6 & 189.4 & \pm & 4.9 & 135.4 & \pm & 10.7 \\
\hline \multirow[t]{4}{*}{2} & HDL-C (mg/dl) & 42.5 & \pm & 3.3 & 43.6 & \pm & 2.8 & 44.7 & \pm & 4.0 & 38.3 & \pm & 2.8 \\
\hline & MDA (umol/L) & 0.53 & \pm & 0.03 & 0.56 & \pm & 0.04 & 0.48 & \pm & 0.04 & 0.54 & \pm & 0.03 \\
\hline & GPX (umol/L) & 2129 & \pm & 151 & 2111 & \pm & 154 & 2292 & \pm & 168 & 2229 & \pm & 160 \\
\hline & FRAP (umol/L) & 743.9 & \pm & 33.6 & 762.9 & \pm & 30.7 & 780.9 & \pm & 32.4 & 756.7 & \pm & 36.0 \\
\hline
\end{tabular}

interventions, reduced a biomarker of DNA oxidative damage (8-hydroxydeoxyguanosine) by $32 \%$ [33]. In a controlled trial where subjects were supplemented with tomato juice but restricted in total fruit and vegetable consumption and exposed to low levels of ozone, researchers found reduced DNA strand breaks compared to placebo controls [34]. Because this study controlled for other phytochemical containing fruits and vegetables, the DNA protection was attributed to tomato juice phytochemicals [34].

The positive correlation between total cholesterol and MDA antioxidant analysis has been reported in studies with hypercholesterolemic subjects compared to normocholesterolemic subjects [35,36]. The MDA assay measures lipid peroxidation products, and a higher level of lipids available to react with peroxidizing agents results in higher MDA values [36,37].

The trend correlating higher FRAP with higher cholesterol levels has not been previously reported. The significance of this trend is speculative, since the FRAP assay measures the oxidation and reduction potential of compounds based on the reduction of the ferric to ferrous iron [38], lipid peroxidation products may have contributed to the oxidation/reduction potential of the reaction.

\section{Conclusions}

Long-term supplementation studies where diet is controlled will probably be necessary to identify the benefits provided by lycopene. There may be real health benefits associated with lycopene especially since it is stored in various tissues and exhibits strong antioxidant activity in vitro $[8,10,39,40]$. Also the body of epidemiological evidence points to the protection provided against cardiovascular disease and some cancers with lycopene containing foods $[11,12,41,42]$. Recent cancer intervention studies have reported beneficial effects on prostate cancer from lycopene food supplementation $[43,44]$. The health benefits associated with diets providing lycopene are most likely long-term. Therefore, the findings of the present study should not be interpreted as a lack of health benefits from regular consumption of lycopene-rich foods.

The interaction between cholesterol levels and antioxidant values needs more research. Contradictory findings 
of this study with other ex vivo antioxidant studies may be due to the cholesterol levels of subjects thus warranting further research.

\section{Competing interests \\ None declared.}

\section{Note}

Mention of trade names or commercial products in this article is solely for the purpose of providing specific information and does not imply recommendation or endorsement by the U.S. Department of Agriculture. All programs and services of the U.S. Department of Agriculture are offered on a nondiscriminatory basis without regard to race, color, national origin, religion, sex, age, marital status, or handicap. The article cited was prepared by a USDA employee as part of his/her official duties. Copyright protection under U.S. copyright law is not available for such works. Accordingly, there is no copyright to transfer. The fact that the private publication in which the article appears is itself copyrighted does not affect the material of the U.S. Government, which can be freely reproduced by the public.

\section{Authors' contributions}

JKC: conception and design of the study, drafted the manuscript, BHA: design of study, editing, PLC:design of the study, statistical analysis, PPV: conception of study, editing, RAB: editing, technical assistance, BAC:conception of study, editing. All authors read and approved the final manuscript.

\section{Acknowledgements}

Research supported in part by a grant from the National Watermelon Promotion Board, Orlando, FL. Researchers would like to acknowledge the following individuals for their technical assistance: Kari Callicoat, Edralin Lucas and Jarrod King.

\section{References}

I. Holden AL, Eldridge AL, Beecher GR, Buzzard IM, Bhagwat SA, Davis CS, Douglas LW, Gebhardt SE, Haytowitz DB, Schakel S: Carotenoid Content of U.S. Foods: An Update of the Database. J Food Comp Anal 1999, 12:169-196.

2. Perkins-Veazie P, Collins JK, Pair SD, Roberts W: Lycopene content differs among red-fleshed watermelon cultivars. J Science of Food and Agric 200I, 81: I-5.

3. Bohm V, Bitsch R: Intestinal absorption of lycopene from different matrices and interactions to other carotenoids, the lipid status, and the antioxidant capacity of human plasma. Eur J Nutr 1999, 38: I I8-125.

4. Shi J, Le Maguer M: Lycopene in tomatoes: chemical and physical properties affected by food processing. Crit Rev Biotechnol 2000, 20:293-334.

5. Gartner C, Stahl W, Sies H: Lycopene is more bioavailable from tomato paste than from fresh tomatoes. Am J Clin Nutr 1997, 66: $116-122$.

6. het Hof KH, de Boer BC, Tijburg LB, Lucius BR, Zijp I, West CE, Hautvast JG, Weststrate JA: Carotenoid bioavailability in humans from tomatoes processed in different ways determined from the carotenoid response in the triglyceride-rich lipoprotein fraction of plasma after a single consumption and in plasma after four days of consumption. J Nutr 2000, 130:1 I89-1 196.
7. Edwards AJ, Vinyard BT, Wiley ER, Brown ED, Collins JK, PerkinsVeazie P, Baker RA, Clevidence BA: Consumption of watermelon juice increases plasma concentrations of lycopene and betacarotene in humans. J Nutr 2003, 133:1043-1050.

8. Di Mascio P, Kaiser S, Sies H: Lycopene as the most efficient biological carotenoid singlet oxygen quencher. Arch Biochem Biophys 1989, 274:532-538.

9. Djuric Z, Powell LC: Antioxidant capacity of lycopene-containing foods. Int J Food Sci Nutr 200I, 52: I43-149.

10. Stahl W, Nicolai S, Briviba K, Hanusch M, Broszeit G, Peters M, Martin HD, Sies H: Biological activities of natural and synthetic carotenoids: induction of gap junctional communication and singlet oxygen quenching. Carcinogenesis 1997, 18:89-92.

II. Rissanen TH, Voutilainen S, Nyyssonen K, Salonen R, Kaplan GA, Salonen JT: Serum lycopene concentrations and carotid atherosclerosis: the Kuopio Ischaemic Heart Disease Risk Factor Study. Am J Clin Nutr 2003, 77:133-138.

12. Gianetti J, Pedrinelli R, Petrucci R, Lazzerini G, De Caterina M, Bellomo G, De Caterina R: Inverse association between carotid intima-media thickness and the antioxidant lycopene in atherosclerosis. Am Heart J 2002, I 43:467-474.

13. Pool-Zobel BL, Bub A, Muller H, Wollowski I, Rechkemmer G: Consumption of vegetables reduces genetic damage in humans: first results of a human intervention trial with carotenoidrich foods. Carcinogenesis 1997, I 8: I847-1850.

14. Riso P, Pinder A, Santangelo A, Porrini M: Does tomato consumption effectively increase the resistance of lymphocyte DNA to oxidative damage? Am J Clin Nutr 1999, 69:712-718.

15. Rao AV,Shen,H.: Effect of low dose lycopene intake on lycopene bioavailability and oxidative stress. Nutrition Research 2002, 22: I|25-II3|.

16. Agarwal S, Rao AV: Tomato lycopene and low density lipoprotein oxidation: a human dietary intervention study. Lipids 1998, 33:98I-984.

17. Kiokias S, Gordon MH: Dietary supplementation with a natural carotenoid mixture decreases oxidative stress. Eur J Clin Nutr 2003, 57: I I35-II 40.

18. Arab L, Steck S: Lycopene and cardiovascular disease. Am J Clin Nutr 2000, 71:1691S-1695S.

19. Fuhrman B, Elis A, Aviram M: Hypocholesterolemic effect of lycopene and beta-carotene is related to suppression of cholesterol synthesis and augmentation of LDL receptor activity in macrophages. Biochem Biophys Res Commun 1997, 233:658-662.

20. Arjmandi BH, Sohn E, Juma S, Murthy SR, Daggy BP: Native and partially hydrolyzed psyllium have comparable effects on cholesterol metabolism in rats. J Nutr 1997, 1 27:463-469.

21. Benzie IF, Strain J]: The ferric reducing ability of plasma (FRAP) as a measure of "antioxidant power": the FRAP assay. Anal Biochem 1996, 239:70-76.

22. Drai J, Bannier E, Chazot C, Hurot JM, Goedert G, Jean G, Charra B, Laurent $G$, Baltassat $P$, Revol A: Oxidants and antioxidants in long-term haemodialysis patients. Farmaco 200I, 56:463-465.

23. Bub A, Watzl B, Abrahamse L, Delincee H, Adam S, Wever J, Muller $H$, Rechkemmer G: Moderate intervention with carotenoidrich vegetable products reduces lipid peroxidation in men.J Nutr 2000, 130:2200-2206.

24. Schwab US, Vogel S, Lammi-Keefe CJ, Ordovas JM, Schaefer EJ, Li Z, Ausman LM, Gualtieri L, Goldin BR, Furr HC, Lichtenstein AH: Varying dietary fat type of reduced-fat diets has little effect on the susceptibility of LDL to oxidative modification in moderately hypercholesterolemic subjects. J Nutr 1998, I 28:1703-1709.

25. Castelo-Branco C, Blumel JE, Roncagliolo ME, Haya J, Bolf D, Binfa L, Tacla $X$, Colodron M: Age, menopause and hormone replacement therapy influences on cardiovascular risk factors in a cohort of middle-aged Chilean women. Maturitas 2003, 45:205-2I 2 .

26. Maruyama C, Imamura K, Oshima S, Suzukawa M, Egami S, Tonomoto M, Baba N, Harada M, Ayaori M, Inakuma T, Ishikawa T: Effects of tomato juice consumption on plasma and lipoprotein carotenoid concentrations and the susceptibility of low density lipoprotein to oxidative modification. J Nutr Sci Vitaminol (Tokyo) 200I, 47:2I3-22I.

27. Carroll YL, Corridan BM, Morrissey PA: Lipoprotein carotenoid profiles and the susceptibility of low density lipoprotein to 
oxidative modification in healthy elderly volunteers. Eur J Clin Nutr 2000, 54:500-507.

28. Lee A, Thurnham DI, Chopra M: Consumption of tomato products with olive oil but not sunflower oil increases the antioxidant activity of plasma. Free Radic Biol Med 2000, 29: 105I- 1055.

29. Takeoka GR, Dao L, Flessa S, Gillespie DM, Jewell WT, Huebner B, Bertow D, Ebeler SE: Processing effects on lycopene content and antioxidant activity of tomatoes. J Agric Food Chem 200I, 49:37I3-37I7.

30. Patterson RE, Haines PS, Popkin BM: Diet quality index: capturing a multidimensional behavior. J Am Diet Assoc 1994, 94:57-64.

31. Torbergsen AC, Collins AR: Recovery of human lymphocytes from oxidative DNA damage; the apparent enhancement of DNA repair by carotenoids is probably simply an antioxidant effect. Eur J Nutr 2000, 39:80-85.

32. Pool-Zobel BL, Bub A, Liegibel UM, Treptow-van Lishaut S, Rechkemmer G: Mechanisms by which vegetable consumption reduces genetic damage in humans. Cancer Epidemiol Biomarkers Prev 1998, 7:891-899.

33. Thompson HJ, Heimendinger J, Haegele A, Sedlacek SM, Gillette C, O'Neill C, Wolfe P, Conry C: Effect of increased vegetable and fruit consumption on markers of oxidative cellular damage. Carcinogenesis 1999, 20:2261-2266.

34. Samet JM, Hatch GE, Horstman D, Steck-Scott S, Arab L, Bromberg PA, Levine M, McDonnell WF, Devlin RB: Effect of antioxidant supplementation on ozone-induced lung injury in human subjects. Am J Respir Crit Care Med 200 I, 164:8I 9-825.

35. Hussein O, Frydman G, Frim H, Aviram M: Reduced susceptibility of low density lipoprotein to lipid peroxidation after cholestyramine treatment in heterozygous familial hypercholesterolemic children. Pathophysiology 200I, 8:2I-28.

36. Sakuma N, Hibino T, Sato T, Ohte N, Akita S, Tamai N, Sasai K, Yoshimata $T$, Fujinami $T$ : Levels of thiobarbituric acid-reactive substance in plasma from coronary artery disease patients. Clin Biochem 1997, 30:505-507.

37. Quasim T, McMillan DC, Talwar D, Sattar N, O'Reilly DS, Kinsella J: Lower concentrations of carotenoids in the critically ill patient are related to a systemic inflammatory response and increased lipid peroxidation. Clin Nutr 2003, 22:459-462.

38. Svilaas A, Sakhi AK, Andersen LF, Svilaas T, Strom EC, Jacobs D.R.,Jr. Ose L, Blomhoff R: Intakes of Antioxidants in Coffee, Wine, and Vegetables Are Correlated with Plasma Carotenoids in Humans. J Nutr 2004, 134:562-567.

39. Erdman J.W.,Jr., Bierer TL, Gugger ET: Absorption and transport of carotenoids. Ann N Y Acad Sci 1993, 69 I:76-85.

40. Parker RS: Absorption, metabolism, and transport of carotenoids. FASEB J 1996, 10:542-55।.

41. Giovannucci E, Rimm EB, Liu Y, Stampfer MJ, Willett WC: A prospective study of tomato products, lycopene, and prostate cancer risk. J Natl Cancer Inst 2002, 94:39I-398.

42. De Stefani E, Boffetta P, Brennan P, Deneo-Pellegrini H, Carzoglio JC, Ronco A, Mendilaharsu M: Dietary carotenoids and risk of gastric cancer: a case-control study in Uruguay. Eur J Cancer Prev 2000, 9:329-334.

43. Kucuk O, Sarkar FH, Sakr W, Djuric Z, Pollak MN, Khachik F, Li YW, Banerjee M, Grignon D, Bertram JS, Crissman JD, Pontes EJ, Wood D.P.Jr.: Phase II randomized clinical trial of lycopene supplementation before radical prostatectomy. Cancer Epidemiol Biomarkers Prev 200I, 1 0:86I-868.

44. Bowen P, Chen L, Stacewicz-Sapuntzakis M, Duncan C, Sharifi R, Ghosh L, Kim HS, Christov-Tzelkov K, van Breemen R: Tomato sauce supplementation and prostate cancer: lycopene accumulation and modulation of biomarkers of carcinogenesis. Exp Biol Med (Maywood) 2002, 227:886-893.

45. U.S. Dept. of Agriculture, Agriculture Research Service: 2000. Servings Intakes by U.S. Children and Adults: 1994-1996, 1998. Online. ARS Community Nutrition Research Group web site available athttp:/ /http//www.barc.usda.gov/bhnrc/cnrg, accessed Sept. 23, 2004.

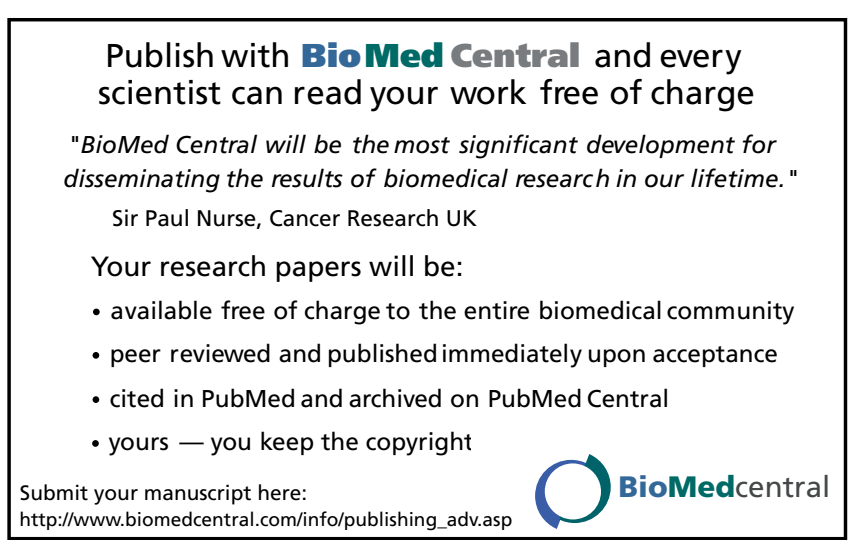

